\title{
Optimization of Metallurgical Factors for Production of High Strength, High Toughness Steel Plate by Controlled Rolling*
}

\author{
By Hiroyoshi MATSUBARA, ,* Tatsumi OSUKA, ${ }^{* *}$ Isao KOZASU, ${ }^{* * *}$ and Koshiro TSUKADA**
}

\section{Synopsis}

This paper describes a part of results of continued developmental activity to obtain optimum chemical composition and processing conditions in the production of high strength steel with high toughness by controlled rolling.

It was noted in laboratory experiment and mill test that niobium most effectively improved the fracture appearance transition temperature $\left({ }_{v} T_{s}\right)$ when a strong controlled rolling was applied, while vanadium was less effective in this respect. Steels containing both of niobium and vanadium also possessed $a{ }_{v} T_{s}$ similar to that of $\mathrm{Nb}$-bearing steels. Addition of $a$ small amount of nickel, chromium, and copper to $\mathrm{Nb}$ - or $\mathrm{V}$-bearing steels enhanced precipitation hardening presumably by lowering the $\gamma \rightarrow \alpha$ transformation temperature without deteriorating the ${ }_{v} T_{s}$. The improvement of ${ }_{v} T_{s}$ by controlled rolling was consistently described by the total rolling reduction given at below $900^{\circ} \mathrm{C}$, and was less dependent on rolling reduction of individual pass.

Lowering carbon content to below a level of $0.07 \%$ in the $\mathrm{Nb}$-bearing steel considerably improved impact shelf energy without any loss in LYS. Transverse shelf energy was also improved by decreasing sulfur content and application of cross rolling. However, an intensive controlled rolling slightly decreased shelf energy.

A combination of the above knowledge has made the production of tough high strength steels possible, and a few such examples of linepipe plate are shown.

\section{Introduction}

Controlled rolling in which a high rolling reduction is applied at lower temperatures has become an important industrial means to produce a large quantity of steel plates with superior toughness for large diameter line pipes and for shipbuilding. ${ }^{1-10}$ ) The particulars of this technique seem, in most cases, to have been established in individual mills through experience, and relevant literatures in the above show a wide variety in details of controlled rolling method and also in its effectiveness in improvement of mechanical properties. Although the most important effect of controlled rolling is an increase of yield stress and an improvement of fracture appearance transition temperature derived from refinement of ferrite grains, the mechanism of this refinement has not been finalized because of the diversity of the background. Grange, ${ }^{11}$ ) for example, attributed the grain refinement to the refinement of austenite after hot deformation. On the other hand, there are reports pointing out that deformation of austenite below its recrystallization temperature is responsible for the refinement of ferrite, which is an effect analogous to thermo-mechanical treatment (TMT). ${ }^{12-15)}$

One of the present authors have previously made an attempt to understand the microstructural events that were taking place in industrial multiple pass roll- ing. ${ }^{16)}$ The result indicated that both the refinement of austenite and the TMT effect were important for the refinement of ferrite structure although the latter predominated in a strong controlled rolling.

As for the influence of chemical composition on the properties of control-rolled steels, it has been pointed out that carbonitride forming elements such as niobium, vanadium, and titanium retard the recrystallization of austenite after hot rolling in such a way that the temperature range where TMT effect takes place is widened, and this, in turn, makes a more effective controlled rolling possible. ${ }^{12-14,17)}$ It was also reported that a lower manganese content raised gamma to alpha transformation temperature $\left(A_{r}{ }^{\prime}\right)$ and that this rendered controlled rolling less effective. ${ }^{17}$ However, the optimization of chemical composition to achieve a best combination of strength and toughness for a low carbon equivalent and particularly suitable for processing by controlled rolling has not been thoroughly sought.

This report deals with an optimization of the chemical composition of control-rolled high strength ferritepearlite steel plate with high toughness (low fracture appearance transition temperature and high shelf energy) that is particularly suitable for high quality line pipes. First, the effect of niobium, vanadium, copper, nickel, and chromium on strength and toughness was studied by laboratory scale controlled rolling. It will be shown that addition of niobium and further addition of copper and chromium are favorable for high strength-toughness combination, and that a decrease in carbon content improves impact value. As for the mill factors affecting transverse shelf energy, the effects of sulfur content and cross rolling are discussed as well as the effect of the degree of controlled rolling on transition temperature. Results of the production of control-rolled steel plates will be shown briefly as examples of successful industrial application of the information obtained in laboratory- and millscale investigations.

\section{The Effect of Alloying Elements on Mechanical Properties of Control-rolled Steels}

A series of laboratory experiments were carried out to seek out an optimum chemical composition to give a good combination of strength and toughness. The basic composition chosen was $0.14 \% \mathrm{C}-0.30 \% \mathrm{Si}-$ $1.30 \% \mathrm{Mn}$ and $\mathrm{Al}$ killed, which was typical of many high strength low alloy steels. Niobium, vanadium,

* $\quad$ Received April 13, 1972.

** Fukuyama Works, Nippon Kokan K. K., Kokan-cho, Fukuyama 720.

*** Technical Research Center, Nippon Kokan K. K., Minamiwatarida-cho, Kawasaki-ku, Kawasaki 210. 
copper, chromium, and nickel were added to this composition separately or in combination in composition ranges shown in Table 1 . Melting was carried out with a $50 \mathrm{~kg}$ induction furnace in air. Besides these steels, $0.50 \% \mathrm{Si}-1.4 \% \mathrm{Mn}-0.045 \% \mathrm{Nb}$ steels with varying carbon content of $0.05-0.13 \%$ were similarly made. Ingots of $150 \mathrm{~mm}$ thickness were rolled preliminarily to $60 \mathrm{~mm}$, air-cooled, and cut to an appropriate size. These pieces were finish-rolled to $12 \mathrm{~mm}$ thickness in the same direction as the preliminary rolling. The schedules of finish-rolling are shown in Fig. 1. Heating temperature was $1250^{\circ}$ or $1150^{\circ} \mathrm{C}$, and rolling was carried out in seven passes of equal reduction of $20 \%$. The rolling temperature was indicated by true surface temperature of steel plates measured by an integrated type radiation pyrometer (Land Pyrometer): hollow symbols in Fig. 1 are the passes whose temperature was thus measured, whereas the solid dots indicate those whose temperature was determined by a pre-established relation of temperature vs. interpass interval. The pass schedule

Table 1. Chemical composition of laboratory melted steels $(w t \%)$

\begin{tabular}{l|cccc} 
& C & Si & Mn & P \\
\hline Nominal & 0.14 & 0.30 & 1.30 & 0.017 \\
Range & $0.13-0.15$ & $0.25-0.35$ & $1.21-1.40$ & $0.011-0.022$ \\
\hline
\end{tabular}

\begin{tabular}{cccccc}
$\mathrm{S}$ & $\mathrm{Nb}$ & $\mathrm{V}$ & $\mathrm{Cu}$ & $\mathrm{Cr}$ & $\mathrm{Ni}$ \\
\hline 0.012 & & & & & \\
$0.007-0.014$ & $0-0.034$ & $0-0.105$ & $0-0.48$ & $0-0.50$ & $0-0.52$
\end{tabular}

\begin{tabular}{cc} 
Sol. Al & T. N \\
\hline 0.02 & 0.007
\end{tabular}

0.015-0.028 0.0057-0.0105

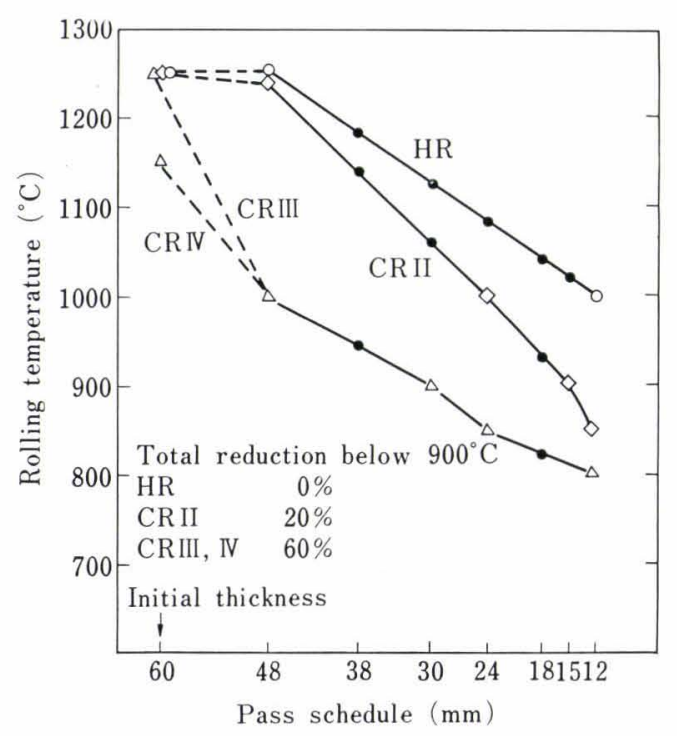

Fig. 1. Hot rolling schedule of laboratory melted steels. Hollow symbols: passes whose temperature was measured

Solid symbols: passes conducted according to predetermined time intervals designated HR roughly corresponds to conventional rolling schedule for $20 \mathrm{~mm}$-thick plates. The CRII is a "weak" controlled rolling in industrial rolling, and the CRIII can be considered as a "strong " controlled rolling. Mechanical properties were tested in transverse direction in all cases. Tensile test pieces were $9 \mathrm{~mm}$-diameter round bar, and Charpy test pieces were $2 \mathrm{~mm} \mathrm{~V}$-notch full size. Charpy test results were presented in terms of the $50 \%$ brittle appearance transition temperature $\left.{ }_{v} T_{s}\right)$ and shelf energy

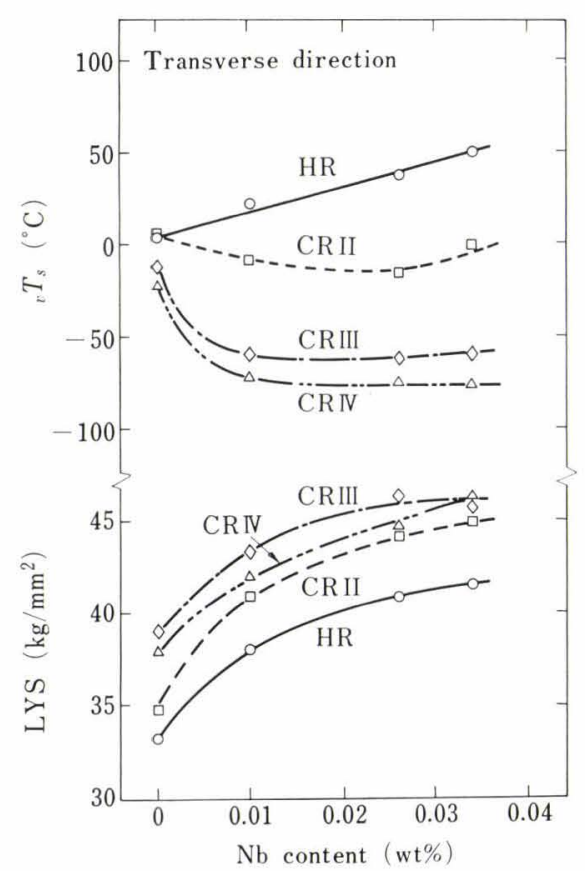

Fig. 2. The effect of niobium on LYS and ${ }_{v} T_{s}$ (fracture appearance transition temperature.)

Laboratory melted $0.14 \mathrm{C}-0.30 \mathrm{Si}-1.30 \mathrm{Mn}$ steels

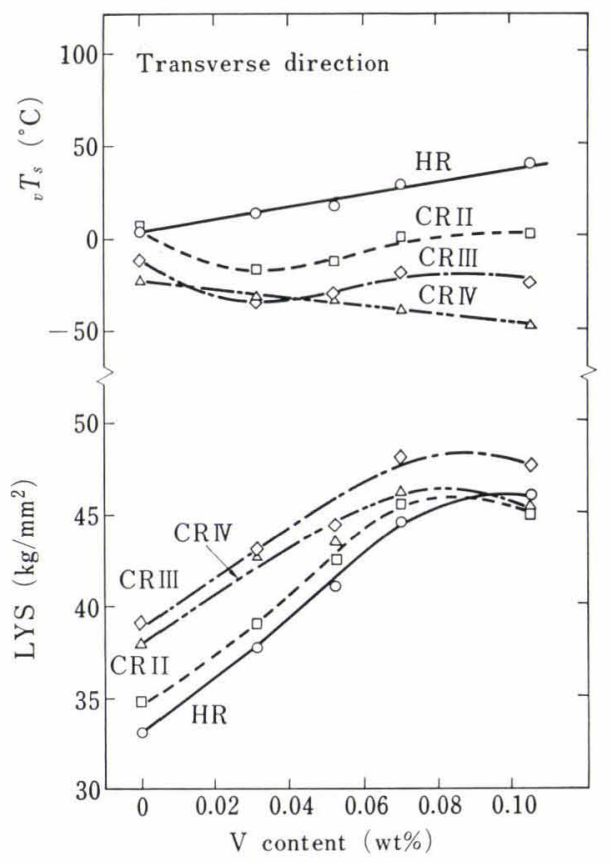

Fig. 3. The effect of vanadium on LYS and ${ }_{v} T_{s}$. Laboratory melted $0.14 \mathrm{C}-0.30 \mathrm{Si}-1.30 \mathrm{Mn}$ steels 
of full ductile region $\left({ }_{v} E_{s}\right)$. Ferrite grain diameter $(d)$ was determined by lineal analysis of about 400 grains.

\section{Niobium and Vanadium}

The effect of controlled rolling was most clearly seen in the increase of lower yield stress (LYS) and in the lowering of ${ }_{v} T_{s}$. Variation of mechanical properties is shown in Figs. 2 and 3, and of microstructure in Photo. 1. Although ferrite grain refinement and resultant improvement of LYS and ${ }_{v} T_{s}$ were noticed in the base steel as the degree of controlled rolling was increased, lowering of ${ }_{v} T_{s}$ was not large compared with mill result perhaps owing to the small overall rolling reduction from ingot to plate. Addition of niobium produced strengthening by precipitation hardening, but it simultaneously brought about deterioration in ${ }_{v} T$ under the condition of high rolling temperature (HR). On the other hand, when the degree of controlled rolling was increased, ${ }_{v} T_{s}$ of niobium-bearing steel was low compared with that of steels without niobium. While this decrease of ${ }_{v} T_{s}$ was apparent even for niobium content as small as $0.01 \%$, further addition beyond this level did not essentially alter the level of ${ }_{v} T_{s}$. Though LYS and TS (tensile strength) were increased with the content of niobium, the rate of increase became smaller above $0.02 \%$. In the case of vanadium, a similar increase in strength was observed, and the rate of this increase was diminished above $0.07 \%$. The ${ }_{v} T_{s}$ of vanadium-bearing steel was also deteriorated compared with that of the base steel when rolling temperature was high (HR). Although controlled rolling improved $T_{s}$ at vanadium contents of 0.03 to $0.05 \%$, this improvement became diminished above this content range. It was concluded that under strong controlled rolling the improvement of ${ }_{v} T_{s}$ by niobium was by far effective than that of vanadium. Lowering the heating temperature prior to hot

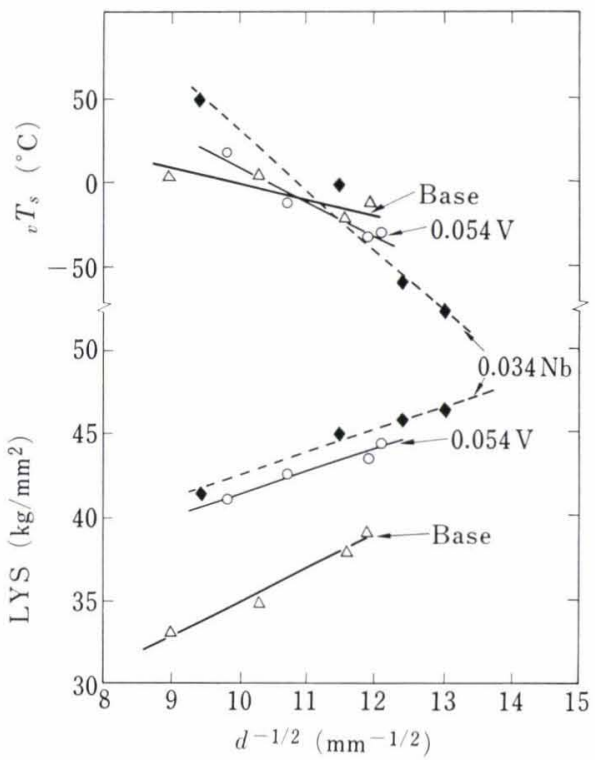

Fig. 4. Examples of grain size dependence of LYS and ${ }_{v} T_{s}$ (Hall-Petch and Cottrell-Petch plots)

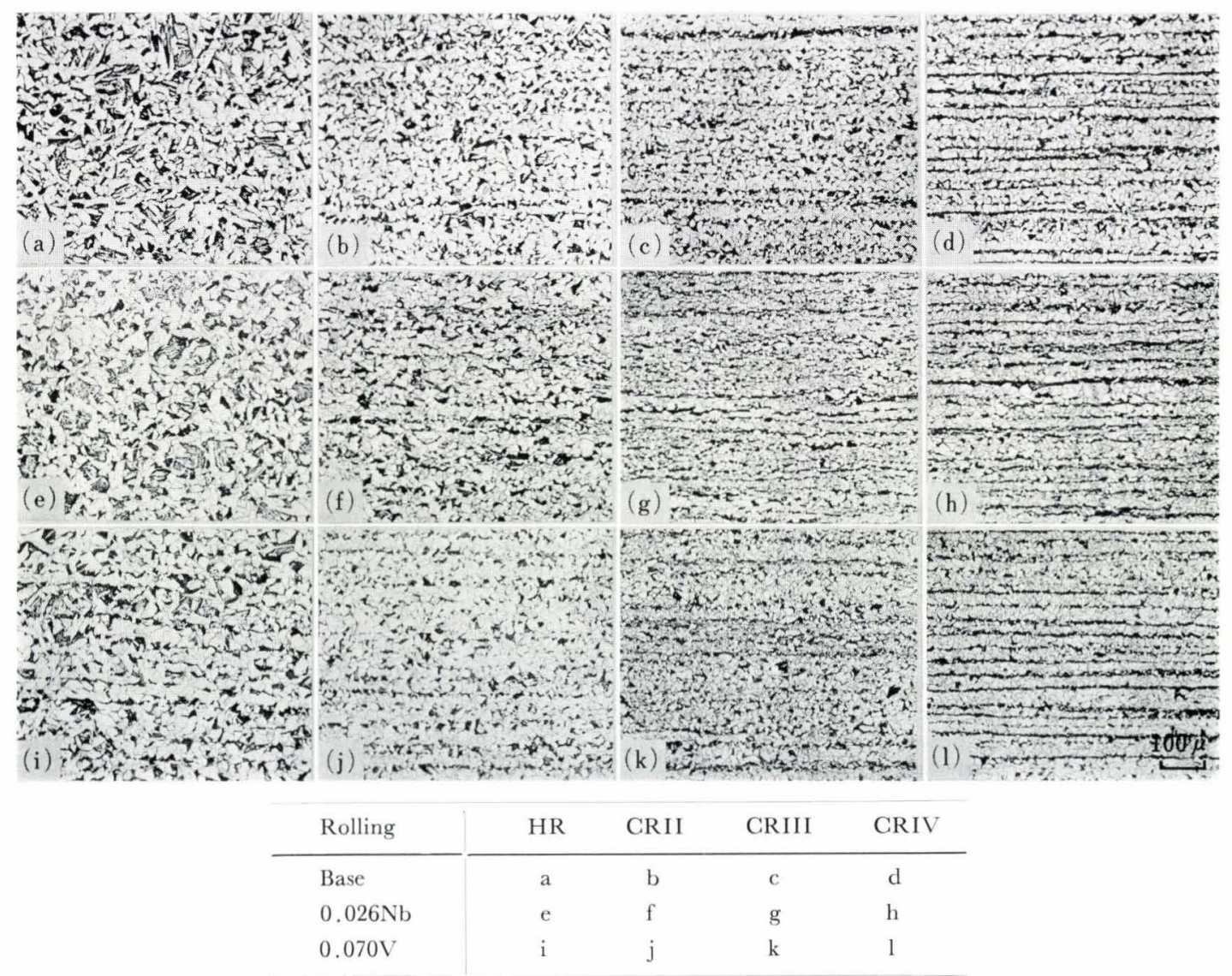

Photo 1. Microstructure of laboratory melted $0.14 \mathrm{C}-0.30 \mathrm{Si}-1.30 \mathrm{Mn}$ steels 
rolling from $1250^{\circ}$ (CRIII) to $1150^{\circ} \mathrm{C}$ (CRIV) produced a slight decrease in both the strength and the ${ }_{v} T_{s}$, but this change was considered insignificant in comparison to the magnitude of the effect of controlled rolling.

The above results may be interpreted primarily in terms of the change in ferrite grain size, and such example is shown in Fig. 4. The grain size dependence coefficient $\left(k_{y}\right)$ of Hall-Petch relation of LYS was $2.0 \mathrm{~kg} / \mathrm{mm}^{3 / 2}$ for the base steel, $1.2-1.7$ for niobium-bearing steels, and 0.6-1.6 for vanadium-bearing steels. When the increment of LYS due to niobium or vanadium was broken down into contributions from grain refinement $\left(\Delta_{\sigma_{G S}}\right)$ and those from precipitation hardening $\left(\Delta \sigma_{p p t}\right)$, the result was as shown in Table 2 for the cases of $0.01 \% \mathrm{Nb}$ and $0.03 \% \mathrm{~V}$. It may be seen that when the degree of controlled rolling was weak, $\Delta \sigma_{p p t}$ was greater than $\Delta \sigma_{G S}$ for both the niobium- and the vanadium-bearing steels. In niobium-bearing steels, $\Delta_{\sigma_{p p t}}$ was decreased under strong controlled rolling, and this decrease was compensated by an increase of $\Delta \sigma_{G S}$. This type of change was less conspicuous in vanadium-bearing steel. The decrease of precipitation hardening by controlled rolling was presumably a result of accelerated precipitation of niobium- and vanadium-carbonitride in austenite resulting in coarse precipitate size due to rolling deformation in temperature range where the supersaturation of these elements were very high.

The grain size dependence of ${ }_{v} T_{s}$ is shown again in Fig. 4. The large improvement of ${ }_{v} T_{s}$ in the niobiumbearing steel by strong controlled rolling can be explained by the grain size dependence of ${ }_{v} T_{s}$ that is large in comparison to those of the base and the vanadium-bearing steels and also by its grain size, which was the smallest attainable by the controlled rolling. ${ }^{17)}$ The reason why the grain size dependence, $\left[d\left({ }_{v} T_{s}\right) /\right.$ $d\left(d^{-1 / 2}\right)$ ], of niobium- or vanadium-bearing steels is larger than that of base steel may be shown in the below. For niobium- or vanadium-bearing steels, it may be seen in Table 2 that the following approximate relationship exists.

$$
\Delta \sigma_{G S}+\Delta \sigma_{p p t} \simeq \text { const } .
$$

From the Cottrell-Petch relation in its simplified form and the Eq. (1), Eq. (2) below is drawn.

$$
\left[\frac{d\left({ }_{v} T_{s}\right)}{d\left(d^{-1 / 2}\right)}\right]_{p p t} \simeq-\left[\frac{d\left({ }_{v} T_{s}\right)}{d\left(d^{-1 / 2}\right)}\right]_{p p t-f r e e}-k_{y}\left[\frac{d\left({ }_{v} T_{s}\right)}{d\left(\Delta \sigma_{p p t}\right)}\right]
$$

where subscripts "ppt" and "ppt-free" designate the

Table 2. Contribution of grain refinement $\left(\Delta \sigma_{G S}\right)$ and precipitation hardening $\left(\Delta \sigma_{p p t}\right)$ to the increase of LYS $\left(\mathrm{kg} / \mathrm{mm}^{2}\right)$

\begin{tabular}{l|rr|rc}
\multirow{2}{*}{$\begin{array}{c}\text { Rolling } \\
\text { condition }\end{array}$} & \multicolumn{2}{|c|}{$0.010 \mathrm{Nb}$} & \multicolumn{2}{c}{$0.033 \mathrm{~V}$} \\
\cline { 2 - 4 } & $\Delta \sigma_{G S}$ & $\Delta \sigma_{p p t}$ & $\Delta \sigma_{G S}$ & $\Delta \sigma_{p p \ell}$ \\
\hline HR & 0 & 4.8 & 0.3 & 4.2 \\
CRII & 1.5 & 3.5 & 0.5 & 3.5 \\
CRIII & 3.5 & 1.5 & 2.0 & 3.0 \\
\hline
\end{tabular}

presence and absence of precipitation hardening respectively. Substituting into Eq. (2) $\left[d\left({ }_{v} T_{s}\right) /\right.$ $\left.d\left(\Delta \sigma_{p p t}\right)\right] \simeq 4^{18}$ and $k_{y} \simeq 1.5$, the values which are supposed to be valid when precipitation hardening is operative, a grain size dependence that approximates the case of vanadium-bearing steel in the present study can be obtained. The $\left.\left[d\left({ }_{v} T_{s}\right) / d^{-\mathbf{1} / \mathbf{2}}\right)\right]_{p p t}$ of niobiumbearing steel was far larger than the value expected from Eq. (2), and this discrepancy may be attributed probably to electron-microscopic substructures and morphology of niobium carbonitride precipitates.

The LYS and ${ }_{v} T_{s}$ for the case of simultaneous addition of niobium and vanadium for the controlled rolling CRIII are shown in the upper portion of Table 3 where contents of niobium and vanadium were interpolated to 0.015 and $0.040 \%$ respectively using Figs. 2 and 3 . For simultaneous addition, the increment of LYS was less than the sum of the increments resulted from individual alloying of niobium and vanadium, and ${ }_{v} T_{s}$ was just comparable to that for single addition of niobium. For niobium-, vanadium-, and niobium-and-vanadium-bearing steels, $d^{-1 / 2}$ was 13 , 12 , and $12 \mathrm{~mm}^{-1 / 2}$ respectively. Therefore, there was no further grain refinement for the simultaneously alloyed steel. These results lead to an inference that difference, (sum of the increments of singly alloyed LYS's) - (increment of LYS of simultaneous alloying) $\simeq 2 \mathrm{~kg} / \mathrm{mm}^{2}$, may be explained by a loss in the contribution due to grain refinement by either niobium or vanadium (\lrcorner$\left.\sigma_{G S}\right)$. Also judging from the absolute value of ${ }_{v} T_{s}$, which was similar to that of niobiumbearing steel, it was thought that substructures and morphology of precipitates in electron-microscopic scale might be similar to those of simple niobiumbearing steel.

\section{Copper, Chromium, and Nickel}

Small amount of copper, chromium, and nickel have often been added to hot rolled or normalized steels in order to increase strength without deteriorating weldability. However, the effect of these elements for the control-rolled steels has not been reported.

Table 3. The effect of alloying elements on LYS and ${ }_{v} T_{s}$ under the rolling condition CRIII

\begin{tabular}{lccc}
\hline & LYS $\left(\mathrm{kg} / \mathrm{mm}^{2}\right)$ & $\Delta \mathrm{LYS}\left(\mathrm{kg} / \mathrm{mm}^{2}\right) *$ & ${ }_{v} T_{s}\left({ }^{\circ} \mathrm{C}\right)$ \\
\hline Base & 39.0 & 5.3 & -12 \\
$0.015 \mathrm{Nb}$ & 44.3 & 5.2 & -60 \\
$0.040 \mathrm{~V}$ & 44.2 & 8.6 & -59 \\
$0.015 \mathrm{Nb}+0.040 \mathrm{~V}$ & 47.6 & 2.9 & -10 \\
\hline $0.25 \mathrm{Cu}$ & 41.9 & 0 & -32 \\
$0.50 \mathrm{Cu}$ & 39.0 & -1.6 & -25 \\
$0.25 \mathrm{Cr}$ & 37.4 & -0.7 & -42 \\
$0.50 \mathrm{Cr}$ & 38.3 & 7.6 & -63 \\
$0.015 \mathrm{Nb}+0.5 \mathrm{Cu}$ & 46.6 & 8.3 & -61 \\
$0.015 \mathrm{Nb}+0.5 \mathrm{Cr}$ & 47.3 & 6.5 & -25 \\
$0.04 \mathrm{~V}+0.5 \mathrm{Cu}$ & 45.5 & 6.3 & -17 \\
$0.04 \mathrm{~V}+0.5 \mathrm{Cr}$ & 45.3 & & \\
\hline
\end{tabular}

* JLYS: difference from the base steel 
Table 3 shows the effect of single addition of copper and chromium up to $0.5 \%$ and of combined addition with niobium or vanadium under CRIII. It is apparent from the middle portion of Table 3 that copper did not exert any meaningful influence on LYS, that chromium slightly lowered LYS, and that the transition temperature was somewhat improved by these elements. When copper or chromium was added to niobium-bearing steels, LYS was increased by 2 to $3 \mathrm{~kg} / \mathrm{mm}^{2}$ with no change in ${ }_{v} T_{s}$. When these elements were added to vanadium-bearing steels, on the other hand, an increase of about $1 \mathrm{~kg} / \mathrm{mm}^{2}$ in LYS was observed, but ${ }_{v} T_{s}$ underwent some deterioration. The above result indicates that combined alloying of copper or chromium with niobium or vanadium results in an increased LYS by cooperative action of these elements. Similar phenomena were observed in all cases of the rolling conditions tested, and the cooperative strengthening was noted also for nickel and copper plus chromium when they were used in combination with niobium or vanadium. It became clear from the above results that single or simultaneous addition of copper, chromium, and nickel in an amount less than $0.5 \%$ in total to niobium-bearing steel made realization of higher strength without deteriorating the ${ }_{v} T_{s}$ possible.

This type of cooperative strengthening has been reported as the effect of manganese in $\mathrm{C}-\mathrm{Si}-\mathrm{Mn}-\mathrm{Nb}$ steels, ${ }^{19)}$ or as the effect of manganese and nickel in $\mathrm{Fe}-\mathrm{V}-(\mathrm{C})$ alloys. ${ }^{20)}$ The additional strengthening effect by these elements was attributed to a finer precipitate size of niobium- or vanadium-carbonitride as a result of lowered $A_{r}{ }^{\prime}$ temperature by these elements. It was confirmed also in the present investigation on the basis of grain size measurement that the additional strengthening was of precipitation hardening type. The measurement of $A_{r}{ }^{\prime}$ temperature with a dilatometer (Formaster-F) after heating to $1200^{\circ} \mathrm{C}$ gave a result shown in Table 4. For example, an addition of $0.5 \%$ copper to niobium bearing steel lowered $A_{r}^{\prime}$ by approximately $100^{\circ} \mathrm{C}$. In comparison with niobium-bearing steels, this lowering was less pronounced in vanadium-bearing steels. Although $A_{r}{ }^{\prime}$ in a simple heating-cooling cycle is different from that where plastic deformation is given in cooling cycle, the tendency of lowered $A_{r}{ }^{\prime}$ is expected to apply qualitatively to cooling after hot rolling. Therefore, the cooperative strengthening in the present case was concluded to be derived from an increased precipitation hardening due to lowered $A_{r}{ }^{\prime}$.

Table 4. Transformation temperatures $\left({ }^{\circ} \mathrm{C}\right)$

\begin{tabular}{llll} 
& $A_{c 1}$ & $A_{c 3}$ & $A_{r}{ }^{* *}$ \\
\hline $0.010 \mathrm{Nb}$ & 710 & 835 & 680 \\
$0.033 \mathrm{~V}$ & 705 & 840 & 640 \\
$0.50 \mathrm{Cu}$ & 700 & 840 & 680 \\
$0.013 \mathrm{Nb}-0.5 \mathrm{Cu}$ & 700 & 838 & 580 \\
$0.036 \mathrm{~V}-0.5 \mathrm{Cu}$ & 695 & 845 & 620
\end{tabular}

* $A_{r}^{\prime}$ : heating $1200^{\circ} \mathrm{C} \times 10 \mathrm{~min}$, cooling rate $90^{\circ} \mathrm{C} / \mathrm{min}$

\section{Carbon}

So far, toughness has been discussed in terms of ${ }_{v} T_{s}$. Another important parameter in toughness is the shelf energy $\left({ }_{v} E_{s}\right)$ in Charpy test, which is directly related to ductility, becoming the lower the more the amount of such second phase particles as elongated sulfide inclusions, pearlite, or cementite. In aluminum-killed steels, elongated inclusions are manganese sulfide whose volume fraction is directly related to the sulfur content in steel. The ${ }_{v} E_{s}$ is not only dependent on the amount of manganese sulfide, but also on the size and shape, which is in turn influenced by ingot size, total rolling reduction, and cross rolling. These factors will be discussed later as the mill factors, and only the influence of carbon content is examined here.

Figure 5 shows the mechanical properties of $0.5 \% \mathrm{Si}-$ $1.4 \% \mathrm{Mn}-0.045 \% \mathrm{Nb}$ steels with varying carbon content when they were rolled under CRIII. It should be noted that yield stress remained almost unchanged when carbon was reduced from 0.13 to $0.05-0.06 \%$ although tensile strength underwent a slight decrease. On the other hand, shelf energy was increased by a factor of 1.5 by this decrease of carbon content. Table 5 shows the change of microstructure caused by change of carbon content. The increase of ${ }_{v} E_{s}$ was

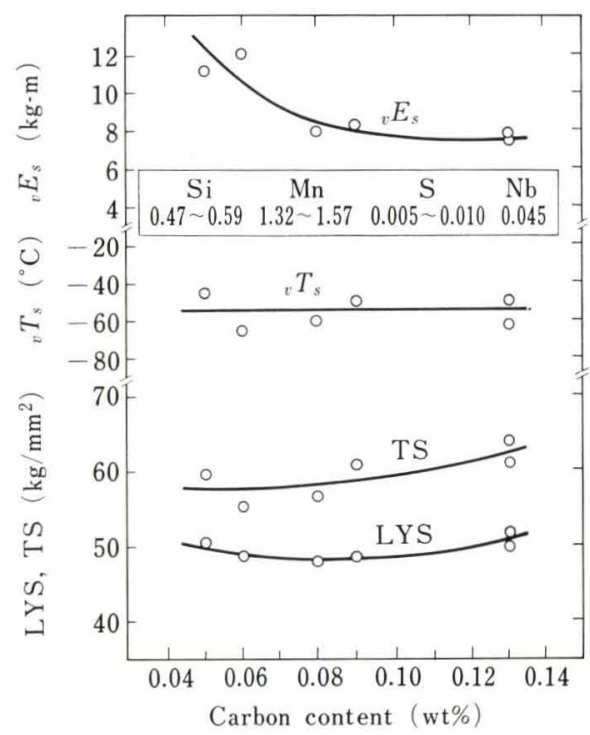

Fig. 5. The effect of carbon content on mechanical properties of laboratory melted steels control-rolled according to schedule CRIII ( $c f$. Fig. 1).

Transverse direction

Charpy specimen: $2 \mathrm{~mm} \mathrm{~V}$-notch full size

Table 5. Variation of ferrite grain diameter and pearlite fraction with carbon content. $0.47-0.59 \mathrm{Si}, 1.32-1.57 \mathrm{Mn}, 0.045 \mathrm{Nb}$. Rolling condition : CRIII

\begin{tabular}{cccc}
$\begin{array}{c}\mathrm{C} \\
(\mathrm{wt} \%)\end{array}$ & $\begin{array}{c}\text { Ferrite grain } \\
\text { diameter }(\mu)\end{array}$ & $\begin{array}{c}\text { Pearlite fraction } \\
(\%)\end{array}$ & \\
\hline $0.05-0.06$ & $4.5-5.2$ & $7-8$ & mixed grain \\
$0.08-0.09$ & $4.8-5.0$ & $19-25$ & \\
0.13 & $4.4-5.0$ & $24-27$ &
\end{tabular}


directly related to the decrease in pearlite fraction. This suggests that the main advantage of PRS (pearlite reduced steel) ${ }^{22)}$ lies in an enhanced shelf energy rather than an improvement in ${ }_{v} T_{s}$.

The fact that LYS was independent on carbon content might stem from an effectively constant ferrite grain size irrespective of carbon content ( $c f$. Table 5). Regarding this fact, the following facts may be pointed out as relevant. ${ }^{17)}$

(1) Steels with low manganese content (typically $0.6 \%$ ) do not produce fine ferrite grains because of their narrow control-rolling temperature range (specifically unavailability of TMT range) as the result of their high $A_{r}{ }^{\prime}$ temperature.

(2) For steels with moderately low $A_{r}{ }^{\prime}$ temperature, rolling immediately above or below $A_{r}{ }^{\prime}$ point results in a virtual grain refinement by substructure formation in ferrite or partial and fine recrystallization of ferrite.

In the present case, the phenomena as described in (1) did not apply because the manganese contents were high. The effect of elevated $A_{r}{ }^{\prime}$ at a low carbon level was presumably offset by the effect as in (2). It was noted that a tendency of mixed grain structures was emphasized at carbon content as low as $0.05 \%$.

\section{The Influence of Mill Rolling Conditions and Examples of Production Result}

Major mill rolling variables that affect mechanical properties are the degree of controlled rolling with respect to ${ }_{v} T_{s}$ and the cross rolling ratio with respect to shelf energy in both longitudinal and transverse direction.

\section{Controlled Rolling and ${ }_{v} T_{s}$}

As already reported, ${ }^{9,16,17)}$ there exists a close correlation between the total rolling reduction below $950^{\circ}$ or $900^{\circ} \mathrm{C}$ and ${ }_{v} T_{s}$, and further, that the rolling reduction of individual pass does not exert appreciable influence. An example is shown in Fig. 6 where a steel containing niobium and vanadium was control-rolled by various amount, though always to $14 \mathrm{~mm}$ thickness, on a plate mill through roughing- and finishing-stands. The rolling temperature here is the corrected true surface temperature of the plate measured by a phototube

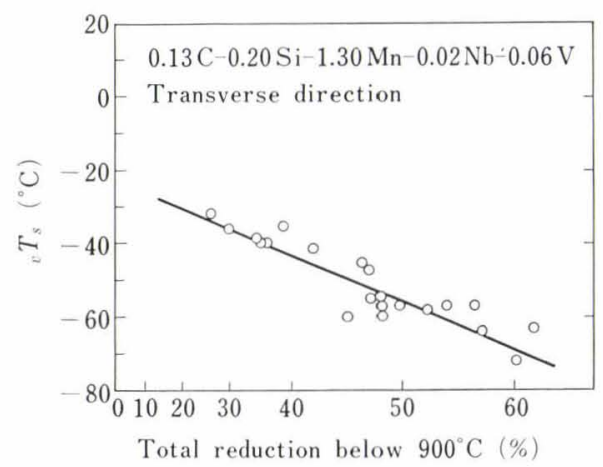

Fig. 6. Relationship between controlled rolling in terms of the total reduction at below $900^{\circ} \mathrm{C}$ and ${ }_{v} T_{s}$ (mill test result)

Thickness: $14 \mathrm{~mm}$ pyrometer. The absolute values of the parameters in a particular correlation curve differed slightly according to mill layout. For a specific mill, however, the controlled rolling vs. ${ }_{v} T_{s}$ relationship as in Fig. 6 was stable and little affected by alloying elements or plate thickness as long as the basic chemical composition was the niobium type. The variation of heating temperature prior to hot rolling in between $1300^{\circ}$ to $1150^{\circ} \mathrm{C}$ had virtually no influence on mechanical properties as long as a sufficient degree of controlled rolling was given.

It was recognized that some precaution had to be taken for rolling schedule of niobium-bearing steels. When the temperature of plate immediately prior to controlled rolling range was too high (for example $1050^{\circ} \mathrm{C}$ ) and the plate had to be cooled off for a prolonged time period for temperature adjustment, the effect of controlled rolling on ${ }_{v} T_{s}$ became diminished. This phenomenon may be understood in the following way. In niobium-bearing steels, the recrystallization temperature of austenite is elevated to about $1000^{\circ} \mathrm{C}$ compared to $900^{\circ}-850^{\circ} \mathrm{C}$ of niobium-free steels. Consequently, the effect of controlled rolling in niobium steels originates mainly from the working of austenite below its recrystallization temperature (the TMT effect). When the temperature of the pass immediately before the controlled rolling range is above $1050^{\circ} \mathrm{C}$, austenite recrystallizes coarse. Coarse austenite tends to deform inhomogeneously in micro scale by rolling below recrystallization temperature (the controlled rolling range of niobium steel). Unless the controlled rolling is extremely heavy, the transformed structure for such a case is mixed grains or Widmanstätten-like abnormal structures depending on the inhomogeneity of the deformation. ${ }^{9,17}$ ) From this reason, the pass schedule prior to controlled rolling should also be designed carefully. The influence of niobium and vanadium on the effect of the mill controlled rolling was quite similar to that of laboratory result, and it may be sufficient to quote examples of $\mathrm{V}$ and $\mathrm{Nb}+\mathrm{V}$ steels (Fig. 7).91

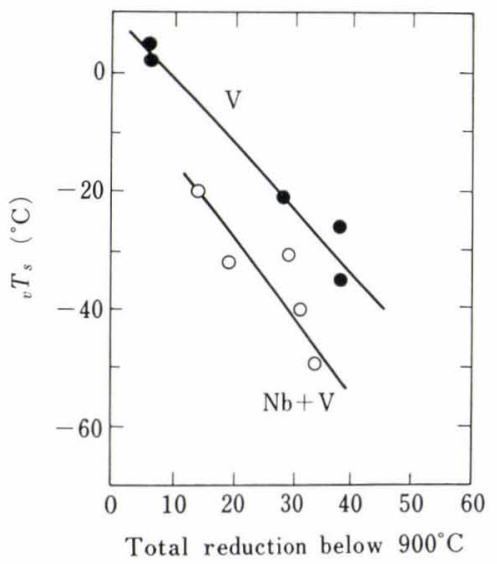

Fig. 7. The effect of alloying elements ( $\mathrm{Nb}$ and $\mathrm{V}$ ) and the degree of controlled rolling on ${ }_{v} T_{s}$ (mill result. $)^{9 \prime}$ Base composition: $0.14 \mathrm{C}-0.24 \mathrm{Si}-1.23 \mathrm{Mn}$ Thickness: $10 \mathrm{~mm}$ 


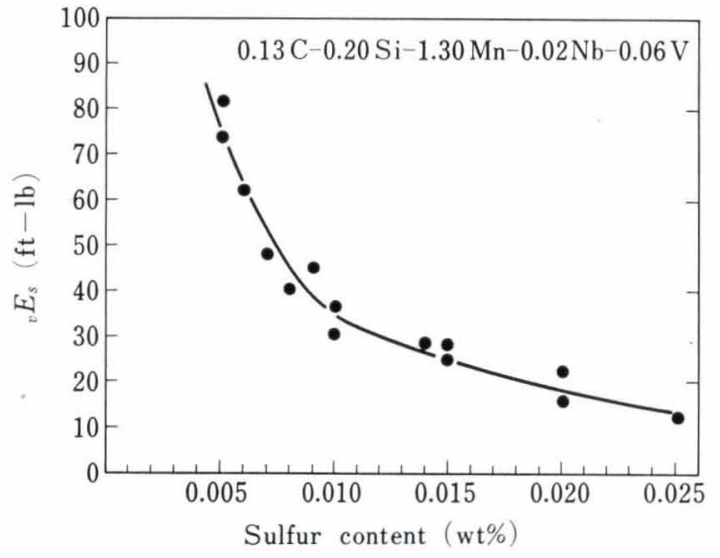

Fig. 8. The effect of sulfur content on transverse shelf energy (mill result)

Thickness: $14 \mathrm{~mm} ; 2 \mathrm{~mm} \mathrm{~V}$-notch full size specimen

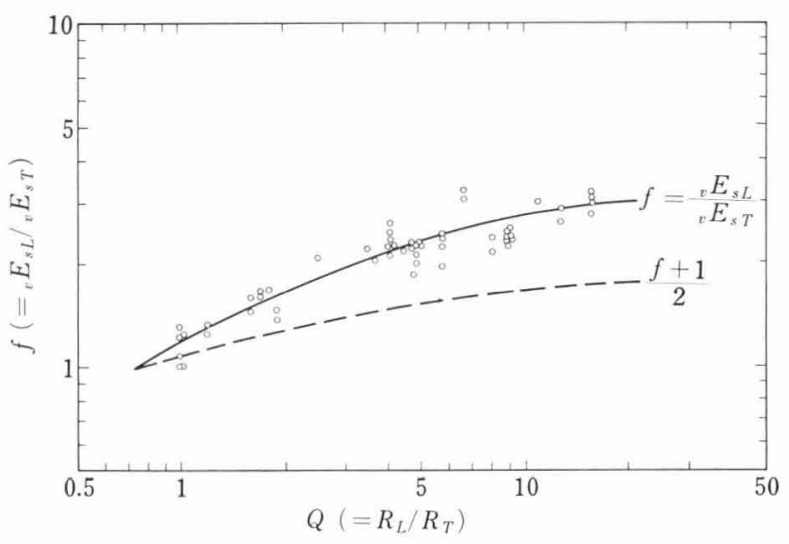

Fig. 9. The ratio of shelf energy, longitudinal to transverse, $(f)$ as a function of cross rolling ratio $(Q)$ (mill result.)

Thickness: 9-15 mm; TS: $55-65 \mathrm{~kg} / \mathrm{mm}^{2}$

\section{Improvement of Shelf Energy}

Figure 8 is an example of the effect of sulfur on transverse ${ }_{v} E_{s}$ under an identical chemical composition and cross rolling ratio. It is apparent that lowering sulfur to below $0.010 \%$ improved shelf energy to a great extent. For a constant sulfur content, on the other hand, a deliberate assignment of rolling ratio (initial thickness/finished thickness) to longitudinal (final rolling) and transverse direction brings about an improvement of transverse shelf energy, which is of practical importance. In typical mill rolling where the overall rolling ratio, the thickness of ingot to that of the finished plate, is 40-50, these exists a relationship between cross rolling ratio $R_{L} / R_{T}(\equiv Q)$ and ${ }_{v} E_{s L} /$ ${ }_{n} E_{s T}(\equiv f)$ as shown in Fig. 9, where $R$ is the rolling ratio, and subscripts $L$ and $T$ indicate longitudinal and transverse direction respectively. When ingot was rolled only in one direction, the value of $f$ was generally $3.0-3.5$. An identical ${ }_{v} E_{s}$ in longitudinal and transverse direction was obtained for $Q=1$ (more exactly, 0.7).

Manipulation of cross rolling ratio can be understood as an act of deliberate distribution of the intrinsic ductility of steel, that is determined by sulfur

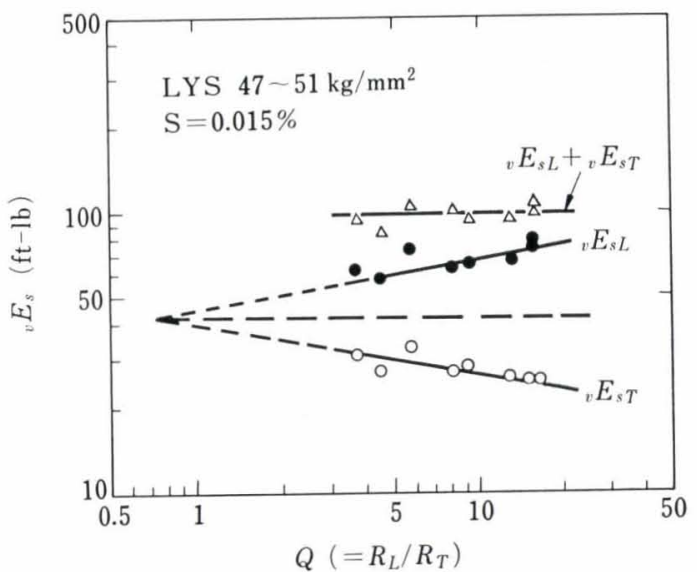

Fig. 10. Variation of longitudinal- and transverse-shelf energy with cross rolling ratio $(Q)$ (mill result.) $0.17 \mathrm{C}-0.13 \mathrm{Si}-1.21 \mathrm{Mn}-0.2 \mathrm{Cu}-0.2 \mathrm{Cr}-0.019 \mathrm{Nb}$. Thickness: $14 \mathrm{~mm}$

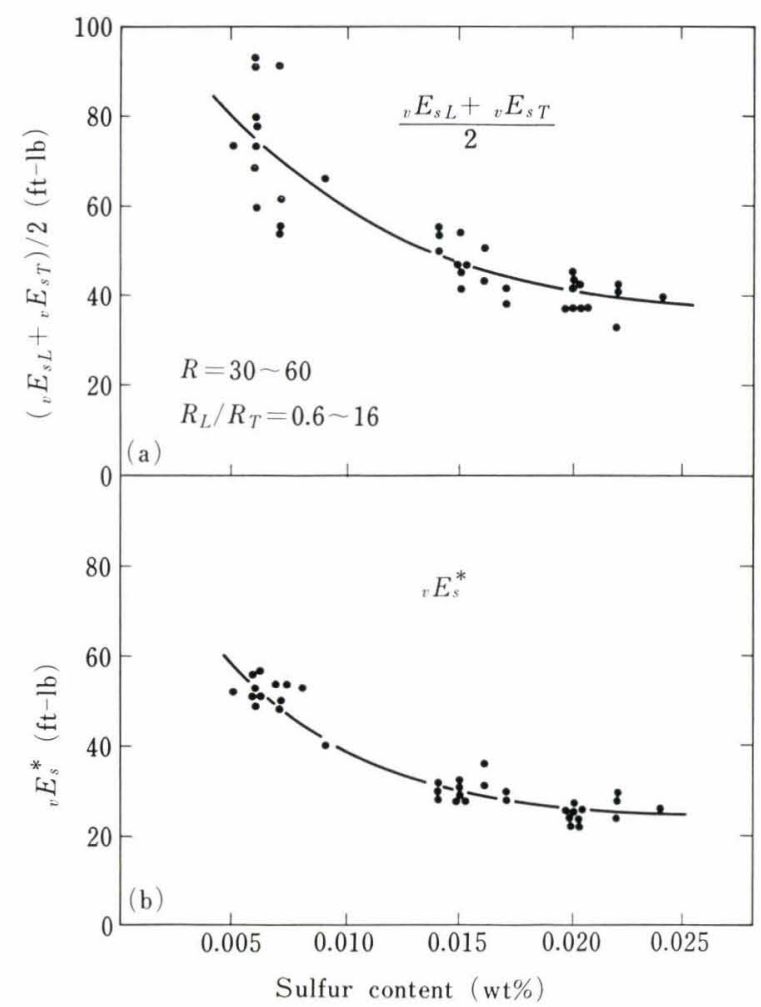

(a) Arithmetic average of longitudinal and transverse shelf energies

(b) Corrected shelf energy $\left({ }_{v} E_{s}^{*}\right)$ according to Eq. (3)

TS: $\quad 55-65 \mathrm{~kg} / \mathrm{mm}^{2} ; 2 \mathrm{~mm} \quad \mathrm{~V}$-notch full size specimen

Fig. 11. Variation of shelf energy with sulfur content (mill result)

content, to longitudinal and transverse directions by controlling the degree of elongation of $\mathrm{MnS}$ in the two directions. Figure 10 illustrates such situation where a certain steel was rolled by various cross rolling ratio. It is clear that arithmetic and geometric averages of ${ }_{v} E_{s}$ in the two directions are nearly constant for the range of cross rolling ratio applied. However, general experience was that at $Q \sim 1$, this constancy broke down resulting in a lower average shelf energy than 
at higher $Q$. This suggests that to give the intrinsic shelf energy the simple average need be modified. From a simple model based on available information on the relationship between $Q$ and ${ }_{v} E_{s}$ 's, the following equation to give the normalized shelf energy ${ }_{v} E_{s}^{*}$ was obtained correcting the arithmatic average of ${ }_{n} E_{s}$ 's for the effect of cross rolling ratio $(Q),{ }^{24}$

$$
{ }_{v} E_{s}^{*}=\frac{{ }_{v} E_{s L}+{ }_{v} E_{s T}}{2} \cdot 1+\alpha(Q+1) / 2 \sqrt{R} \cdot Q
$$

where $\alpha$ is a constant, and $R$ is the overall rolling reduction. Figure 11 (a) is a direct plot of the arithmetic average of ${ }_{v} E_{s}$ with varying $Q$ as a function of sulfur content. While Fig. 11 (a) shows a considerable scatter, in Fig. 11 (b), which is a plot of normalized

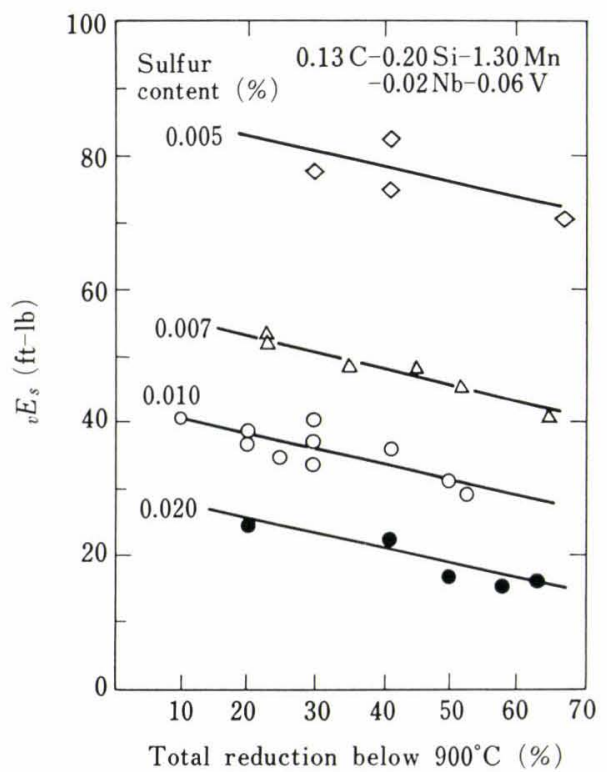

Fig. 12. The effect of the degree of controlled rolling on transverse shelf energy (mill result)

Thickness: $14 \mathrm{~mm}$; $2 \mathrm{~mm} \quad \mathrm{~V}$-notch full size specimen
${ }_{v} E^{*}$ calculated from Eq. (3), the correlation with sulfur content is improved. Once this kind of correlation is established, it may become possible to determine the sulfur level and the cross rolling ratio required for a particular shelf energy.

So far, variation of shelf energy has been discussed for the cases of constant controlled rolling conditions. However, the degree of controlled rolling itself had an influence on ${ }_{v} E_{s}$ as shown in Fig. 12 where ${ }_{v} E_{s}$ tended to be lowered as the degree of controlled rolling was increased. One cause for this variation may be an increase of strength with controlled rolling. Another may be the occurrence of micro-fissurings, which were found more numerously on broken surface of Charpy specimen as controlled rolling was intensified. This fissuring was caused by $\mathrm{MnS}$ more elongated at lower rolling temperatures. ${ }^{23)}$

\section{Examples of Production Results by Controlled Rolling}

Based on information described so far, it has become possible to prescribe steel composition and rolling conditions for a given specification. It may be summarized in a simplified manner as follows:

LYS, TS, and $C_{e q} \rightarrow$ chemical composition

${ }_{v} T_{s} \rightarrow$ degree of controlled rolling (chemical composition)

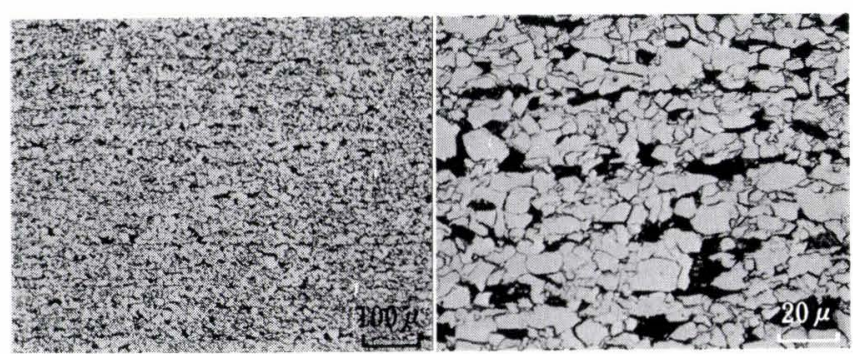

Photo. 2. Microstructure of control-rolled line pipe steel Steel $D$ in Table 6

Table 6. Properties of control-rolled steel plates

(a) Chemical composition (wt \%)

\begin{tabular}{|c|c|c|c|c|c|c|c|c|c|c|c|c|}
\hline Steel & C & $\mathrm{Si}$ & $\mathrm{Mn}$ & $\mathrm{P}$ & $\mathrm{S}$ & $\mathrm{Cu}$ & $\mathrm{Cr}$ & $\mathrm{Nb}$ & V & Sol. Al & T.N & $C_{e q}{ }^{*}$ \\
\hline$A$ & 0.17 & 0.37 & 1.28 & 0.017 & 0.017 & 0.20 & 0.15 & 0.028 & - & 0.032 & 0.006 & 0.383 \\
\hline$B$ & 0.18 & 0.13 & 1.30 & 0.019 & 0.016 & - & - & 0.016 & - & 0.043 & 0.005 & 0.396 \\
\hline C & 0.13 & 0.20 & 1.36 & 0.014 & 0.006 & 0.08 & 0.25 & 0.019 & 0.061 & 0.005 & 0.006 & 0.356 \\
\hline$D$ & 0.08 & 0.21 & 1.34 & 0.014 & 0.005 & - & 0.20 & 0.032 & - & 0.037 & 0.006 & 0.303 \\
\hline
\end{tabular}

$* C_{e q}=\mathrm{C}+\mathrm{Mn} / 6$

(b) Processing condition and mechanical properties* (transverse direction)

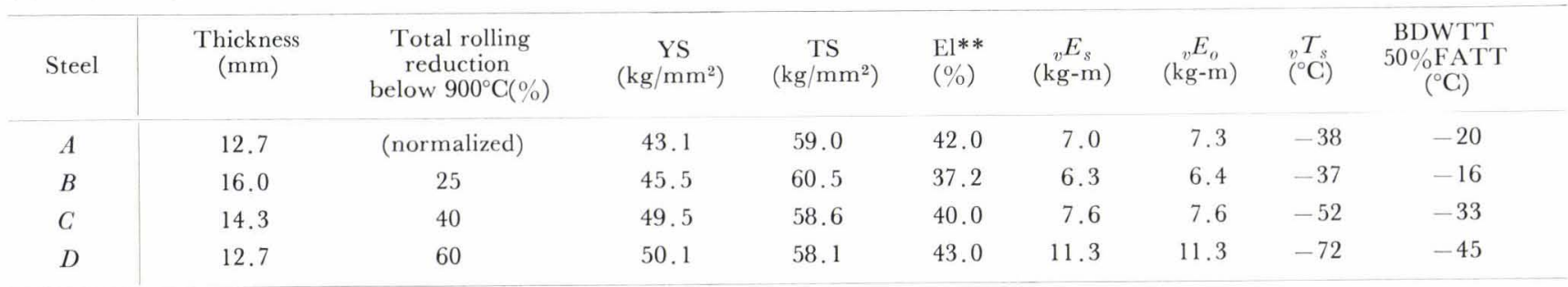

* Full size Charpy specimen ** $G L=50 \mathrm{~mm}$ 
${ }_{v} E_{s}$ or impact value at any specified temperature $\rightarrow \mathrm{S} \%$ and cross rolling ratio

The examples of plates for high tensile strength line pipes (API-5LX, X60, and X65) produced on this procedure are shown in Table 6 and Photo. 2. Steel $A$ that was produced by normalizing treatment, which used to be a standard method when a good toughness was required, is shown for comparison. All other steels are the controlled rolled products. Steel $B$ is niobium-bearing, though not of any particular compositional consideration, and was lightly control-rolled. Steel $C$ is a desulfurized low carbon $(\mathrm{Cu})-\mathrm{Cr}-\mathrm{Nb}-\mathrm{V}$ type steel to which a heavier controlled rolling was applied. Steel $D$ is also a desulfurized $\mathrm{Cr}-\mathrm{Nb}$ type with lower carbon than of Steel $C$, and the controlled rolling was the heaviest. All of these steels were melted in basic oxygen converters and cross rolled to various extent. It is evident that mechanical properties of control-rolled steels are excellent in that they achieved higher strength with lower carbon equivalent compared to normalized steel. The transition temperatures of control-rolled steels are far lower than that of normalized steel and are almost in the level of quenched and tempered steels. Similarly the 50\% SA-FATT (shear area-fracture transition temperature) of BDWTT (Battelle Drop Weight Tear Test), which is considered important for line pipes, is also very low. Only the shelf energy tended to be generally lower than that of normalized steels, but this can be remedied by lowering the carbon content, desulfurization, and cross rolling as evidenced by Steels $C$ and $D$. The level of general properties of Steel $D$ is indeed such that had been thought unattainable without quench-and-tempering.

\section{Summary}

Optimum chemical compositions for steels of controlled rolling type to give a good combination of high strength and superior toughness were investigated by laboratory scale experiment. In mill scale investigations, the effect of controlled rolling on fracture appearance transition temperature $\left({ }_{v} T_{s}\right)$ and the effect of both sulfur content and cross rolling on shelf energy $\left.{ }_{v} E_{s}\right)$ were studied. Also mentioned is the results of production conducted based on the above investigations.

(1) When steels were control-rolled, the most effective element to lower ${ }_{v} T_{s}$ was niobium. Although vanadium was less effective in lowering transition temperature in comparison to niobium, ${ }_{v} \mathcal{T}_{s}$ of $\mathrm{Nb}+\mathrm{V}$ steels were similar to that of niobium steels. Addition of niobium or $\mathrm{Nb}+\mathrm{V}$ was considered to be the best way to increase strength without deteriorating ${ }_{v} T_{s}$. Small addition of copper, nickel, or chromium had no effect on strength, but when used in combination with niobium or vanadium, they produced additional precipitation strengthening due to niobium or vanadium. Lowering carbon content down to $0.07 \%$ im- proved ${ }_{v} E_{s}$ considerably.

(2) The effect of controlled rolling on ${ }_{v} T_{s}$ was consistently described by the total rolling reduction below $900^{\circ} \mathrm{C}$. As this total reduction increased, ${ }_{v} T_{s}$ was lowered accordingly.

(3) Desulfurization improved the transverse ${ }_{v} E_{s}$. There existed a stable correlation between cross rolling ratio and the ratio of ${ }_{v} E_{s}$ longitudinal to transverse. The knowledge of these relations facilitates an estimation of ${ }_{v} E_{s}$ in longitudinal and transverse direction for any given condition. Heavier controlled rolling was noted to decrease ${ }_{v} E_{s}$ slightly.

(4) The plates produced by controlled rolling posessed higher strengths combined with better low temperature toughnesses for a low carbon content than those of the normalized steels.

\section{REFERENCES}

1) R. W. Vanderbeck: Weld. J., 37 (1958), 114s.

2) J. H. van der Veen: Rév. Mét., 65 (1968), 1.

3) W. Zimnik, J. Petersen, and R. Blecher: Bänder Bleche Rohr, 10 (1969), 407.

4) W. vor dem Esche and A. Drevermann: Stahl u. Eisen, 90 (1970), 179.

5) R. Jamieson and J. W. Thomas: ISI Publication No. 104 (1967), 299.

6) J. W. Thompson: ISI Publication No. 104 (1967), 173.

7) T. George: ISI Publication No. 104 (1967), 123.

8) J.J. Irani, D. Burton, J. D. Jones, and A. B. Rothwell: ISI Publication No. 104 (1967), 73.

9) H. Kubota, I. Kozasu, T. Shimizu, S. Murai, and Y. Kaneko: Nippon Kokan Giho, 46 (1969), 205.

10) M. Civallero and C. Parrini: Proc. ICSTIS, (1971), 759, Suppl. Trans. ISIJ.

11) R. A. Grange: Fundamentals of Deformation Processing, ed. by W. A. Backofen, et al., (1964), 299, Syracuse Univ. Press.

12) R. Priestner, C. C. Earley, and J. H. Rendall: JISI, 206 (1968), 1252.

13) K. J. Irvine, T. Gladman, J. Orr, and F. B. Pickering: JISI, 208 (1970), 717.

14) R. B. G. Yeo, A. G. Melville, P. E. Repas, and J. M. Gray: J. Metals, 20 (1968), No. 6, 33.

15) T. Maruyama, H. Kageyama, and H. Sekine: Tetsu-toHagané, 57 (1971), S625.

16) I. Kozasu: Trans. ISIJ, 12 (1972), 241.

17) I. Kozasu, T. Shimizu, and K. Tsukada: Trans. ISIJ, 12 (1972), 305.

18) T. Araki, A. Nanba, T. Aoki, and M. Kanao: Tetsu-toHagané, 56 (1970), 1501.

19) H. Kubota, I. Kozasu, H. Kido, and T. Shimizu: Tetsuto-Hagané, 54 (1968), 954.

20) H. G. Suzuki, T. Sato, and M. Tanino: Proc. ICSTIS, (1971), 1082, Suppl. Trans. ISIJ.

21) J. M. Gray and R. B. G. Yeo: Trans. ASM, 61 (1968), 255.

22) W. E. Duckworth, R. Phillips, and J. A. Chapman: JISI, 203 (1965), 1108.

23) I. Kozasu and H. Kubota: Trans. ISIJ, 11 (1971), 321.

24) H. Matsubara, T. Osuka, I. Kozasu, and K. Tsukada: Trans. ISIJ, 12 (1972), 477. 